\title{
Refuge: Rethinking Refugee Policy in a Changing World
}

\author{
Alexander Betts and Paul Collier \\ New York: Oxford University Press, 2017. 281 pages.
}

The world is facing a crisis of displaced people more devastating than any it has seen since the Second World War. 65 million people, about 45 million of whom are internally displaced, have been forced to flee from their homes because of disaster and violence. 20 million have crossed an international border to find safety (1). Upon doing so, they become, under the Western world's definition, refugees. Separated from their homelands, their resources, and often their support systems, these people seek security in new lands as they wait for the violence at home to cease and for their societies to stabilize. Despite increasingly vitriolic rhetoric to the contrary, there is broad consensus among citizens and policy-makers of Western nations that the wealthier, more powerful countries of the world have a clear moral duty to offer aid, shelter, and nurture to these people. The methods and practices that UN member states and host countries are currently using to do so, however, are "even by [their] own metrics... failing badly" (7). Against this backdrop of fragility, atrocity, and failure, Alexander Betts and Paul Collier offer up their ambitious book Refuge: Rethinking Refugee Policy in a Changing World as an explanation of how this crisis came about and as a sketch of potential structural and practical solutions through the rethinking of international refugee policy and the provision of autonomy to the world's refugees through the restoration of their right to work away from home.

Alexander Betts is the Leopold W. Muller Professor of Forced Migration and International Affairs at the University of Oxford. Paul Collier is a Professor of Economics, Public Policy, and Government at Oxford and a Fellow of St. Antony's College. Given their fields, Refuge is not a work of Islamic studies but rather of economics, public policy, and refugee studies. It is nonetheless relevant to Islamic social sciences in its careful consideration of present human and political issues in the Muslim world and in the potential impact its ideas could have on the lives of millions of Muslim people. The book came into being out of their experience designing a pilot project with the Jordanian government that resulted in the Jordan Compact, which not only granted refugees the right to work in certain economic 
zones in Jordan but created employment opportunities for 200,000 of them (xii-xiii). It is written for a "generalist audience" of policy-makers, scholars, and concerned members of the public (xiv).

Refuge is divided into nine chapters which are sorted into three unequal sections entitled "Why Is There a Crisis?", "The Rethink", and "History, The Remake." Part I details the subject at hand-defining a refugee and considering how an individual comes to be one, providing a history of refugee policy and arguing for its outdatedness, and recounting the recent events that led to the current Syrian crisis. Part II, the longest section, orders much of the rhetorical content of the book and presents Betts' and Collier's "four big new ideas": that rescue of displaced persons is an ethical duty; that havens should be nearby, accessible, and financed by wealthier countries; that refugees should be able to work and corporations should be incentivized to participate in the economies of haven nations; and that the economic support needed for refuge can also be used to incubate the recovery process (188-189). Part III, only one chapter long, plays back the Syrian refugee crisis through the new governmental and economic frameworks that the authors suggest to illustrate the difference they would have made and can still make in future disasters.

Betts and Collier are not vague about their purposes for writing Refuge. Under the present refugee regime, namely the United Nations High Commission for Refugees, the basic goals of providing protection for refugees and finding durable, long-term solutions (namely repatriation to the country of origin, resettlement to a third country, or local integration into the host country) are not being met (7). The current humanitarian style of housing refugees in large, decrepit camps indefinitely-along with the present political understanding of a refugee as one who is displaced from their country of origin due to a "well-founded fear of being persecuted for reasons of race, religion, nationality, membership of a particular social group or political opinion" which has remained basically unchanged since the 1950s (4) - makes the present system outdated, ineffective, and abusive. The primary cause of displacement today is not persecution but mass violence that results from the collapse of fragile states (states that lack sufficient legitimacy in the eyes of their citizens and the capacity to enforce their rule in order to maintain themselves), and consequently new solutions are desperately needed (17-18).

Given the above circumstances, the authors posit a number of important guiding changes to refugee policy, starting with changing the definition of a "refugee": 
One way of grounding how we should identify refugees in a changing world is through the concept of force majeure - the absence of a reasonable choice but to leave. More specifically, the threshold for refuge would be: fear of serious physical harm. And the test would be: when would a reasonable person not see her- or himself as having a choice but to flee?

Such an overhaul of the Western definition of a refugee would, in theory, open lanes for Western acceptance of more displaced persons and attune governments and organizations to address the problems that are actually present. Even more importantly, however, the authors rethink the whole system of refuge. At its heart, the book aims to sketch out a solution that would provide protection for all refugees for the duration of the conflicts in their home states and to create for them effective "routes out of limbo" (205). This would be accomplished through responsible coordination of international burden-sharing and through fully incorporating business and civil society into refugee policy (214-215). Their principal argument is to leave behind the "humanitarian silos" of camps in favor of the integration of refugees into the economies of host nations through granting them the right to work (a right almost universally denied) in "development zones" which would, in turn, be integrated into the global economy by way of corporate investment and trade policy $(173-175,205)$. Rather than waste away in camps, refugees would be educated, trained, and coordinated into positions that coincide with the skills they bring with them into displacement. Policy would be put into place to entice corporations to enter into host nations to provide opportunities for development and to enter into recently repatriated areas to maximize reconstruction and smooth economic recovery. International and non-government organizations would be utilized to provide proper support in collaboration with these autonomy-increasing moves. If successful, Betts and Collier's model would foster a winning situation for all parties: refugees would find safety and autonomy; host countries would receive an influx of workers and entrepreneurs; wealthier nations could be better utilized, providing resources rather than refuge to people who would need to travel thousands of miles to reach them and could potentially die on the journey; and fragile states could be repatriated with a better educated and more experienced workforce post-conflict.

While the authors' model is enticing, it seems to problematically gloss over the protections of the refugees-turned-workers. Without substantive reference to proper oversight or an effective workplace monitoring system, 
one could cynically claim that what Betts and Collier are really presenting is a model for the exploitation of the most vulnerable sector of humanity-an opportunity for Western corporations to score cheap labor by assimilating the already displaced and destitute into their machinations. Betts and Collier very briefly dismiss this concern near the end of the work. "Given the combination of international-organization oversight, media scrutiny, and the reputational concerns of large corporations, the risk of abuse is remote" (236). They add that the status quo, in which refugees already work illicitly in camps and cities, is much more fertile ground for iniquities. While this point is noted, it seems naively optimistic to assume that media scrutiny is enough to guarantee worker protections or that corporations will concern themselves with the dignity of workers once the media moment passes. A worker-based model of oversight that maximizes transparency and communication throughout the corporate ladder similar to what has been put forward by the Worker-Driven Social Responsibility Network, member organizations of which have been widely recognized for protecting workers' rights in ways that are both effective for workers and beneficial for participating corporations, could be an important introduction to Betts and Colliers' rethought havens.

While the reforms Betts and Collier propose in Refuge are not perfect, one must recognize that deliberation over their legitimacy is time-bound. It is essential to make changes as quickly as possible given that the current crisis has seen countless people die and many more stagnate in camps and urban squalor $(54,69)$. Each day that passes carries with it the weight of more Western apathy and indecision. In this climate, Betts and Collier's new vision for efficient and dignified refuge-one that is even now seeing some success through the Jordan Compact-is a welcome contribution.

Wesley Snedeker

Master of Divinity Student Chicago Theological Seminary 